July 2012

\title{
Multidisciplinary Treatment for Conversion Disorder in an 8 Year Old Girl
}

\author{
Jen Wildpret \\ Wake Forest University, jwildpret@gmail.com \\ Sebastian Kaplan \\ Wake Forest University, sgkaplan@wfubmc.edu
}

Follow this and additional works at: https://jdc.jefferson.edu/jeffjpsychiatry

\section{Let us know how access to this document benefits you}

\section{Recommended Citation}

Wildpret, Jen and Kaplan, Sebastian (2012) "Multidisciplinary Treatment for Conversion Disorder in an 8 Year Old Girl," Jefferson Journal of Psychiatry. Vol. 24 : Iss. 1 , Article 3.

DOI: https://doi.org/10.29046/JJP.024.1.003

Available at: https://jdc.jefferson.edu/jeffjpsychiatry/vol24/iss $1 / 3$

This Article is brought to you for free and open access by the Jefferson Digital Commons. The Jefferson Digital Commons is a service of Thomas Jefferson University's Center for Teaching and Learning (CTL). The Commons is a showcase for Jefferson books and journals, peer-reviewed scholarly publications, unique historical collections from the University archives, and teaching tools. The Jefferson Digital Commons allows researchers and interested readers anywhere in the world to learn about and keep up to date with Jefferson scholarship. This article has been accepted for inclusion in Jefferson Journal of Psychiatry by an authorized administrator of the Jefferson Digital Commons. For more information, please contact: JeffersonDigitalCommons@jefferson.edu. 


\section{Multidisciplinary Treatment for Conversion Disorder in an 8 Year Old Girl}

Jen Wildpret D.O., PGY5

Sebastian Kaplan Ph.D. 
The term "conversion" originates from Sigmund Freud's historic doctrine on hysteria in which he describes how anxiety can be "converted" into physical symptoms. ${ }^{1}$ The Diagnostic and Statistical Manual of Mental Disorders defines conversion disorder as being comprised of symptoms involving voluntary motor or sensory function which suggest a neurological or other general medical condition that cannot be fully explained after appropriate medical exploration, and are not consciously feigned or produced. The initial onset or exacerbation of symptoms is preceded by psychological stressors. It is rare for the onset to occur before age 10 years. ${ }^{2}$ Symptoms will generally remit after about two weeks from the onset date, especially if hospitalized and up to one-quarter of patients will have a recurrence within one year. Certain symptoms, such as paralysis and blindness, can be indicative of a good prognosis, while symptoms such as seizures are not. ${ }^{2}$ Leary reviewed multiple case histories of childhood-onset conversion disorder and found that follow-up studies show full recovery in $85-97 \%$ of children and favorable prognostic indicators included recent symptom onset, single symptom complaint, early recognition and healthy premorbid personality functioning. ${ }^{3}$ Pehlivanturk and Unal also reviewed long term follow-up studies of children and adolescents with conversion disorder and concluded that although there can be a favorable outcome in these patients, mood and/or anxiety disorders are commonly encountered as patients recover from the conversion symptoms. ${ }^{4}$ 
Stonnington, et al suggest that adult treatment is best focused on identifying risk factors, simple behavioral interventions, physical therapy, reassurance, working with the patient's family and helping the patient verbalize distress. ${ }^{5}$ Other treatment options geared towards adults include insight-oriented supportive therapy, psychodynamic psychotherapy, hypnotherapy, anxiolytics and behavioral relaxation exercises. ${ }^{6}$

Due to the rare nature of conversion disorder in children under 10 years of age, there is limited information on beneficial treatments that directly targets this population. Although it was possible to apply several of Stonnington's treatment recommendations for adults with conversion disorder, this patient's age-limited cognitive development as well as the short-term inpatient environment made it difficult to apply such treatments as insight-oriented supportive therapy or psychodynamic psychotherapy. ${ }^{7}$

\section{CASE REPORT}

Lucy was an 8-year-old Caucasian female with a history of shaken baby syndrome at 3 months of age resulting in bilateral subdural hematomas which then required bilateral VP shunt placement for hydrocephalus. Lucy was fully functional and asymptomatic until four weeks prior to her admission to the pediatric behavioral health unit. It was during those four weeks that she had two hospitalizations to the pediatric and neurology services for work up of sudden 
onset inability to walk, back spasms, urinary incontinence and headaches. EMG, abdominal and head CTs as well as an MRI of the spine, EEG and lumbar puncture were all negative. A neurosurgery consultation determined there was no need for shunt revision. Her biologic parents stated that Lucy had also regressed to prior child-like behavior such as asking to be carried and for her "Sippy cup." Lucy had multiple somatic complaints mainly consisting of headache, back and knee pain, as well as pain when touched. She also requested much assistance with toileting and bathing. Her parents described personality changes consisting of increased irritability, crying spells and combativeness. Lucy had also recently started biting her lips and fingernails to the point that they would bleed and required topical antibiotic treatment. Recent stressors included her family relocating (locally) and bullying by peers during summer camp about one month prior to admission. Also, during a family trip about three weeks prior to hospitalization, Lucy became ill and consequently was told by her grandmother that she was ruining her mother's vacation.

As previously stated, Lucy had a complex medical and social history. The diagnosis of shaken baby syndrome was the result of physical abuse by her biologic father. Her father was out of the home for several years while serving a prison sentence due to the abusive behavior but moved back in with the patient and her biologic mother upon release. Other medical history includes surgical 
correction for right exotropia at a young age. Lucy was the only child for this couple and has no half- or step-siblings. She was the product of a normal, full-term pregnancy without any reported complications. She performed well socially and academically in school with the support of an individualized education plan (IEP).

Lucy was an underweight Caucasian girl of average intelligence. She was initially uncooperative as displayed by multiple behavioral outbursts when asked to do such things as walking, participating in physical therapy, and other group activities. Her mood was anxious, as evidenced by her fear of separation and clinginess to her mother. Her affect was congruent with her mood. Her speech was of normal rate and fluency. Her thoughts were concrete and goal directed. She showed poor insight and judgment.

On physical exam, patient's pupils were equal, round and reactive to light and her extra-ocular muscles were intact. Her skin was warm and dry without evidence of lesions or bruising. There was no evidence of clubbing, cyanosis, or edema and she exhibited a full range of motion in all four extremities. It was difficult to evaluate her gait secondary to her being uncooperative with the initial evaluation, but she would bear weight with assistance.

Members of the multidisciplinary treatment team included the following: faculty child psychiatrist, child psychiatry fellow, clinical psychologist, recreational therapist, social worker, nursing staff and medical students. 
Lucy was started on sertraline and buspirone to target anxiety symptoms and divalproex sodium for management of mood instability and chronic headaches. She was also toileted every three to four hours. Initially, she required two people to assist her with ambulation and feeding. Nutrition and physical therapy were consulted to work with the patient throughout most of her stay.

Lucy had several seizure-like events while hospitalized. A head CT without contrast showed increasing ventricular size consistent with slightly worsened hydrocephalus though no evidence of significant sulcal effacement or acute mass effect and resolved left posterior convexity extra-axial CSF collection. An EKG showed no contributing abnormalities. A continuous 24 hour EEG, during which time the patient did have several events, suggested the episodes were nonepileptic in nature. Neurosurgery felt she did not require shunt revision.

Initially, Lucy exhibited difficulty responding to the inpatient unit's behavior management program which included a positive reinforcement system and the use of time out to deescalate tantrum episodes. A particular challenge was managing Lucy's behavior after mother's visits. Although the interactions were positive, Lucy had poor separation followed by worsening behavior and tantrums after visiting hours. As a result, the treatment team, with mother's endorsement, included an additional component to the behavior plan, namely, to make mother's visits contingent upon the patient's behavior. For example, if Lucy demonstrated a 
positive attitude and cooperated with staff and peers, then staff notified mother to arrange her visits.

The initial family therapy consultation between Lucy's parents and the clinical psychologist focused on gathering history, as well as eliciting parents' concerns about patient's functioning and their identified parental struggles. Parents described dysfunction in the family in multiple areas. The patient's mother reported being over-attentive to Lucy while under-attentive to her own needs. Lucy's mother described a tendency to quickly "fix" problems and to alleviate any negative emotions that occurred for Lucy as soon as possible. Father expressed genuine care for the family but openly shared his feelings of incompetence in meeting Lucy's needs and often choosing to detach himself from family involvement. Both parents described strain in their marital relationship, using terms such as "boring" and "routine".

Subsequent family therapy consultations focused on strategies that parents and staff found successful while on the unit, as well as methods of adapting these strategies to the home environment. For instance, the psychologist encouraged neutral responses from parents when reacting to toileting accidents. Although the parents expressed initial difficulty ignoring tantrums, they found that Lucy quickly learned age appropriate methods of communicating and meeting her needs. Parents expressed interest in replicating the unit's behavior management program at home 
using a "star chart." The psychologist suggested several strategies in creating a home-based positive reinforcement system, such as frequent opportunities for success initially with a gradual increase in demands over time. The parents also expressed a commitment to address concerns in their marriage.

\section{DISCUSSION}

As is consistent with prior research ${ }^{8}$ our patient's symptoms of conversion disorder appeared to arise from several psychosocial stressors, including marital strain between her parents, being the subject of a verbal altercation between her mother and grandmother as well as peer bullying and transitioning into a new family home. However, unlike other reported cases, our patient had symptoms persist beyond two weeks, indicating a higher level of severity. These unique factors contributed to the need for a personalized multidisciplinary treatment encompassing a biopsychosocial model, which was ultimately successful for Lucy.

The biologic approach to treatment involved ruling out organic causes of Lucy's symptoms through consultation with neurology for EEG and seizure work, and with neurosurgery to assess functionality of the VP shunts. Dietetics and physical therapy was also involved to help with nutrition and physical conditioning. Psychotropic medications were also initiated to help with symptoms management. 
The behavioral component of the treatment plan, which included time-out, was particularly effective for Lucy as she was highly motivated by attention from others. Lucy gradually exhibited improvement in global functioning, including increased cooperation with staff and peers. Had Lucy been prone to self-injurious behaviors, then time-out would not have been appropriate as the potential for harm would have been too great.

Stonnington endorses that "family therapy interventions help the patient and family recognize and address key issues that may be fueling the symptoms. ${ }^{, 5}$ In our case study, a large component of the treatment plan did incorporate Lucy's parents so that they could continue to enforce the behavior modifications at home. Lucy's parents showed a high level of motivation to learn and integrate the treatment techniques which was particularly helpful for her father feeling more empowered in his role. The family consultations also helped her parents to collaborate together in meeting their daughter's needs.

Our case study is limited due to the unknown effects that the shaken baby syndrome had on our patient's neurologic and psychiatric development. The reasoning as to why our patient's visual conversion was not resolved remains unclear. Since the time of hospital discharge, our patient has undergone multiple evaluations and opinions from neurologists, neurosurgeons and neuroophthamologists, all of which have failed to find any deficits in Lucy's visual 
pathways. Future research could focus on any potential links between having a history of shaken baby syndrome and later-life sudden onset blindness.

Other areas for future research could include the use of hypnotherapy as an additional component to the multidisciplinary treatment approach. As Stonnington mentions, "conversion symptoms and hypnosis (can) involve common neurologic pathways," therefore the addition of hypnosis in the treatment of a child with conversation disorder could potentially help to expedite the healing process. ${ }^{5}$ Most of the research for this has been done with adults, therefore, more specific data on children and hypnotherapy is warranted.

\section{ACKNOWLEDGEMENTS}

There are no author disclaimers to report. 


\section{SOURCE INFORMATION}

\section{REFERENCES}

1. Breuer, J, Freud, S: Studies in hysteria. 1895.

2. American Psychiatric Association. Diagnostic and statistical manual of mental disorders, $4^{\text {th }}$ edn, text revision. Arlington, VA: APA, 2005.

3. Leary, PM: Conversion disorder in childhood - diagnosed too late, investigated too much? Journal of the Royal Society of Medicine 2003; 96:436-438.

4. Pehlivanturk, B, Unal, F: Conversion disorder in children and adolescents - A 4-year follow-up study. Journal of Psychosomatic Research 2002;52:187-191.

5. Stonnington, CM, Barry, JJ, Fisher, RS. Conversion disorder. American Journal of Psychiatry. 2006;163:1510.

6. Sadock, BJ, Sadock, VA. Kaplan \& Sadock's synopsis of psychiatry, $9^{\text {th }}$ edn. Philadelphia, PA: Lippincott Williams \& Wilkins, 2003.

7. Piaget, J: Play, dreams and imitation in childhood. New York, NY: WW Norton \& Company, Inc, 1962.

8. Brasic, JR: Conversion disorder in childhood. German Journal of Psychiatry 2002: 5(2):54-61. 